\title{
Estimation of a single probit line from multiple toxicity test data
}

\author{
Wuk-Hee Hong*, Peter G. Meier and Rolf A. Deininger \\ Dept. of Environmental and Industrial Health, School of Public Health, University of Michigan, \\ Ann Arbor, Michigan, U.S.A.
}

(Received 28 January 1987; revision received 21 July 1987; accepted 25 August 1987)

$\mathrm{LC}_{50}$ values for the same compound and the same species may vary considerably within a laboratory and between laboratories. These differences are usually attributed to variable test conditions and response of the test organisms to the toxicant. Furthermore, the lack of standardization for aquatic toxicity testing may contribute to the variability in $\mathrm{LC}_{50}$ values.

To employ toxicity data for regulatory purposes, it may be useful to report one single $\mathrm{LC}_{50}$ value and its associated confidence interval, instead of several $L_{50}$ values for each test substance. To accomplish this, a procedure for combining probit lines from several toxicity tests was developed by modifying the maximum likelihood probit method with inclusion of the technique for parallel line probit analysis. The resulting single probit line from this method is referred to as a "grand probit line' and takes into account separate test results. To ease the calculation a BASIC program was developed for an IBM PC.

Key words: Probit analysis; Aquatic bioassay; Effluent regulation; Computer program; $\mathrm{LC}_{50} ; \mathrm{EC}_{50}$; Diquat

\section{INTRODUCTION}

An acute toxicity test examines the toxic effects of short-term exposure of aquatic organisms to a test substance. The organisms are exposed to several concentrations for designated time intervals, and mortality or immobility for each group is recorded. From these data an $\mathrm{LC}_{50}$ or $\mathrm{EC}_{50}$ value is estimated employing mainly probit analysis. The statistics involved are the estimation of the best fit dose-response line, and the evaluation of the adequacy of the fitted line (Buikema et al., 1982).

Correspondence to: P.G. Meier, Dept. of Environmental and Industrial Health, School of Public Health, University of Michigan, Ann Arbor, MI 48109, U.S.A.

${ }^{*}$ Current address: Korea Electric Power Corporation Research Center, Chemistry and Environmental Dept. 73-1 In-Dong Dong-Ku, Daejeon, Korea. 
One disadvantage of probit analysis for this situation is that only one data set is considered for probit line estimation. Repetitive experiments by the same researcher or those carried out in other laboratories (with the same toxicant and same species), will generate a number of different probit lines and $\mathrm{LC}_{50}$ values. Because of the variabilities of the individual test results it is not statistically acceptable to obtain one representative $\mathrm{LC}_{50}$ by simply averaging the values from different tests. Hence, several $\mathrm{LC}_{50}$ values or a range are usually presented. As an example, four consecutive exposure tests carried out in our laboratory using the same toxicant and species yielded $\mathrm{LC}_{50}$ values with a moderate range. However, the $95 \%$ confidence intervals were rather wide (Table I).

Hence, a statistical procedure that generates one $\mathrm{LC}_{50}$ value and its confidence interval by incorporating multiple test data would greatly enhance summarizing toxicity test results for research and regulatory purposes. It is the attempt of this paper to propose a methodology that combines several probit lines into a 'grand probit line' which provides a better estimate of the representative toxicity characteristics of a designated compound on the same test species.

\section{PROCEDURES FOR GRAND PROBIT LINE ESTIMATION}

The concept for 'grand probit line' estimation was developed by modifying the maximum likelihood (ML) probit method and incorporating the technique for parallel line probit analysis (Finney, 1964, 1971; Hubert, 1984). The following steps elucidate the computational procedure for the grand probit line estimation.

(1) Raw data (e.g., log dose $(X)$ and percent response at each dose level in each test) are tabulated and the observed probit $(Y)$ is obtained according to one of the conventional probit methods.

(2) For each test, an unweighted regression is used to estimate the coefficients of the log dose probit line.

(3) A common slope of the above regression lines can be calculated from the slopes of individual lines by employing the reciprocals of the variances as weights by the following:

\section{TABLE I}

Results of four 48-h toxicity tests utilizing same toxicant and same species. (See Table II for raw data).

\begin{tabular}{lllll}
\hline Test No. & Probit equation & $\mathrm{LC}_{50} \mathrm{mg} / \mathrm{I}$ & $95 \%$ C.I. $\mathrm{mg} / 1$ & $\chi^{2 *}$ \\
\hline 1 & $Y=3.205 X-0.427$ & 49.38 & $37.10-65.71$ & 1.65 \\
2 & $Y=2.521 X+1.022$ & 37.82 & $26.63-53.70$ & 0.94 \\
3 & $Y=3.448 X-0.717$ & 45.51 & $34.93-59.31$ & 0.07 \\
4 & $Y=3.340 X-0.502$ & 44.41 & $34.60-58.71$ & 2.08 \\
\hline
\end{tabular}

$$
{ }^{*} \chi_{0.95 .3}^{2}=7.815 \text {. }
$$


$b=\frac{i_{i=1}^{m} \Sigma b_{i} / V\left(b_{i}\right)}{\underset{i=1}{\mathbf{m}} \Sigma 1 / V\left(b_{i}\right)}$

where $b_{i}=$ slope of $i$ th test probit line; $V\left(b_{i}\right)=$ variance of $b_{i}$; and $m=$ number of tests.

(4) The intercept $a_{i}$ of the regression line with the common slope for each test is estimated by:

$\bar{Y}_{i}=a_{i}+b \bar{X}_{i}$

$\mathrm{a}_{i}=\bar{Y}_{i}-b \bar{X}_{i}$,

where $\bar{Y}_{i}$ and $\bar{X}_{i}$ are the means of the observed probit and log dose in each test, respectively.

(5) From the above regression equations, expected probits $\left(Y^{\prime}\right)$ are estimated for all tests. Following ML procedures (Hubert, 1984), working probits ( $\left.\mathrm{y}^{\prime}\right)$ (Remark 2 below) and their associated weights (Remark 1 below) are calculated. Finally $\Sigma n w$, $\Sigma n w X, \Sigma n w y^{\prime}, \Sigma n w X^{2}, \Sigma n w y^{\prime 2}$, and $\Sigma n w X y^{\prime}$ for each test are computed ( $\Sigma_{j=1}^{k}$, where $k=$ number of exposures).

Remark 1: In estimation theory the weight assigned to a proportion ( $p$ ) of a group is $n w$; where $n=$ number of test organisms in each exposure and $w=1 / P Q ; P$ is the probability of the response by a test $\operatorname{organism}(Q=1-P)$. For $Y=\operatorname{probit}(p)$, the corresponding weight is $n w$ where:

$w=\frac{f^{2}}{P Q}$.

Here, $f$ is the ordinate (frequency domain) value in a standard normal frequency function for a given value of $Y^{\prime}$, that is:

$f=\frac{1}{\sqrt{2 \pi}} \mathrm{e}^{-\left(Y^{\prime}-5\right)^{2} / 2}$

and $P$ is estimated by the equation below for the normal model:

$P=Y_{-\infty}^{\prime} \frac{5 \mathrm{e}^{-\mathrm{t}^{2} / 2}}{\sqrt{2} \pi} d t=\Phi\left(Y^{\prime}-5\right)$,

where $Y^{\prime}$ is the expected probit (Hubert, 1984).

Remark 2: The equation for the expected probit is:

$Y^{\prime}=a+b X$, 
where $a$ and $b$ are the current estimates of the intercept and slope, respectively (Hubert, 1984). The working probit $y^{\prime}$ is defined by the relation:

$y^{\prime}=Y^{\prime}+\frac{p^{-P}}{f}$

(6) $S_{X X}, S_{y^{\prime} y^{\prime}}$ and $S_{X y^{\prime}}$ of each test are now calculated:

$S_{X X}=\Sigma n w X^{2}-\left(\left(\sum n w X\right)^{2} / \Sigma n w\right)$

$S_{y^{\prime}{ }^{\prime}}{ }^{\prime}=\Sigma n w y^{\prime 2}-\left(\left(\sum n w y^{\prime}\right)^{2} / \Sigma n w\right)$

$S_{X y^{\prime}}=\Sigma n w X y^{\prime}-\left(\left(\sum n w X\right)\left(\Sigma n w y^{\prime}\right) / \Sigma n w\right)$,

where the summation is over the exposures (Hubert, 1984). By knowing the slope of ML probit line for each test, $b_{i}={ }_{i} S_{X y}{ }^{\prime} /{ }_{i} S_{X X}$, the intercept is obtained from eq. (2):

$\bar{y}_{i}^{\prime}=a_{i}+b_{i} \bar{X}_{i}$

$\therefore a_{i}=\bar{y}_{i}^{\prime}-b_{i} \bar{X}_{i}$.

(7) The parallelism of the ML probit lines obtained above is tested as follows:

$$
\begin{aligned}
& A=\text { total } \chi^{2} \\
& \left.=\Sigma S_{y^{\prime} y^{\prime}}-\left(\Sigma S_{X y^{\prime}}\right)^{2} /\left(\Sigma S_{X X}\right) \text { (d.f. }=m(d-2)+(m-1)\right) \\
& B=\text { sum of individual test } \chi^{2} \\
& =\Sigma\left(S_{y^{\prime} y^{\prime}}-S_{X y}{ }^{\prime 2} / S_{X X}\right)(\text { d.f. }=m(d-2))
\end{aligned}
$$

$A-B=\chi^{2}$ for parallelism (d.f. $=m-1$ ), where $m=$ number of tests; $d=$ number of exposures in each test.

If the test for parallelism is rejected the procedures for the grand probit line estimation should not be continued (Finney, 1971).

(8) A common slope of the ML probit lines is calculated from eq. (1) with $V\left(b_{i}\right)$ $=1 / S_{X X}$. By knowing $\bar{X}_{i}$ and $\bar{y}^{\prime}{ }_{i}$ and applying the common slope $b$, an improved estimate of the ML probit line with the common slope is calculated for each test. The individual $\log \left(\mathrm{LC}_{50}\right)$ values $\left(M_{i}\right)$ are calculated from these probit equations:

$$
\begin{aligned}
& \bar{y}_{i}^{\prime}=a_{i}+b \bar{X}_{i} \\
& \left.a_{i}=\bar{y}\right)_{i}-b \bar{X}_{i} \\
& M_{i}=\left(5-a_{i}\right) / \mathrm{b} .
\end{aligned}
$$


(9) The variance of each $\log \left(\mathrm{LC}_{50}\right)\left(M_{1}, M_{2}, \ldots, M_{m}\right)$ is calculated by:

$V\left(M_{i}\right)=\frac{1}{b^{2}}\left[\frac{1}{i \Sigma n w}+\frac{\left(M_{i}-\bar{X}_{i}\right)^{2}}{i^{s} X X}\right]$,

where ${ }_{i} \Sigma n w$ is $\Sigma n w$ for the $i$ th line (Finney, 1971).

(10) The heterogeneity of the separate estimates of $\log \left(\mathrm{LC}_{50}\right)$ may be tested with appropriate chi-square:

$$
\begin{gathered}
\chi^{2}=M_{1}{ }^{2} / V\left(M_{1}\right)+M_{2}{ }^{2} / V\left(M_{2}\right)+\ldots+M_{m}{ }^{2} / V\left(M_{m}\right) \\
-\frac{\left[M_{1} / V\left(M_{1}\right)+M_{2} / V\left(M_{2}\right)+\ldots+\left(M_{m} / V\left(M_{m}\right)\right]^{2}\right.}{1 / V\left(M_{1}\right)+1 / V\left(M_{2}\right)+\ldots+1 / V\left(M_{m}\right)},
\end{gathered}
$$

with degrees of freedom $=m-1$.

If this test of heterogeneity is accepted, the procedure should not be continued.

(11) A mean $\log \left(\mathrm{LC}_{50}\right)$ is calculated using reciprocals of the variances as weights:

$$
\mathrm{M}=\frac{M_{1} / V\left(M_{1}\right)+M_{2} / V\left(M_{2}\right)+\ldots+\left(M_{m} / V\left(M_{m}\right)\right.}{1 / V\left(M_{1}\right)+1 / V\left(M_{2}\right)+\ldots+1 / V\left(M_{m}\right)} .
$$

A grand probit line for this toxicant is calculated using the common slope, $b$, and the mean $\log \left(\mathrm{LC}_{50}\right), M$ from the probit line equation:

$Y=a+b X$

$a=5-b M$.

(12) The confidence interval of $M$ is obtained by computing its standard error (Finney, 1971):

$V(M)=\frac{1}{\sum_{i=1}^{m} 1 / V\left(M_{i}\right)}$

$s_{M}=\sqrt{V(M)}$

The $95 \%$ confidence interval of the $\mathrm{LC}_{50}$ is $M \pm 1.96 \times s_{M}$.

\section{SAMPLE CALCULATION}

A BASIC program named GRANDPRO was developed to ease the computational steps shown above. This program was written by modifying the PROBIT program for the estimation of the ML probit line equation (Hubert and Schoch, 1984). 
TABLE II

Mortality data and working probits generated by the GRANDPRO program. Ten fish were exposed to each treatment.

\begin{tabular}{|c|c|c|c|c|c|c|c|}
\hline $\begin{array}{l}\text { Test } \\
\text { No. }\end{array}$ & $\begin{array}{l}\text { Log dose } \\
X\end{array}$ & Death & $\begin{array}{l}\text { Percent }^{\mathrm{a}} \\
\text { mortality }\end{array}$ & $\begin{array}{l}\text { Observed } \\
\text { probit } Y\end{array}$ & $\begin{array}{l}\text { Expected } \\
\text { probit } Y^{\prime}\end{array}$ & $\begin{array}{l}\text { Working } \\
\text { probit } y^{\prime}\end{array}$ & $\begin{array}{l}\text { Weight } \\
w\end{array}$ \\
\hline \multirow{6}{*}{1} & 2.0000 & 10 & & & 5.9825 & 6.6443 & 0.2241 \\
\hline & 1.9031 & 7 & 66.7 & 5.4303 & 5.6552 & 5.4155 & 0.5977 \\
\hline & 1.7782 & 6 & 55.6 & 5.1394 & 5.2332 & 5.1388 & 0.6322 \\
\hline & 1.6021 & 5 & 44.4 & 4.8606 & 4.6384 & 4.8675 & 0.6326 \\
\hline & 1.3010 & 1 & 10.0 & 3.7183 & 3.6217 & 3.7250 & 0.3445 \\
\hline & control & 1 & & & & & \\
\hline \multirow{6}{*}{2} & 2.0000 & 9 & 90.0 & 6.2817 & 6.3303 & 6.2800 & 0.3428 \\
\hline & 1.9031 & 8 & 80.0 & 5.8415 & 6.0030 & 5.8286 & 0.4939 \\
\hline & 1.7782 & 7 & 70.0 & 5.5240 & 5.5810 & 5.5235 & 0.5759 \\
\hline & 1.6021 & 4 & 40.0 & 4.7471 & 4.9862 & 4.7493 & 0.6222 \\
\hline & 1.3010 & 3 & 30.0 & 4.4760 & 3.9695 & 4.6030 & 0.6010 \\
\hline & control & 0 & & & & & \\
\hline \multirow{6}{*}{3} & 2.0000 & 9 & 88.9 & 6.2208 & 6.1551 & 6.2182 & 0.3640 \\
\hline & 1.9031 & 8 & 77.8 & 5.7645 & 5.8278 & 5.7631 & 0.5136 \\
\hline & 1.7782 & 7 & 66.7 & 5.4303 & 5.4058 & 5.4306 & 0.5949 \\
\hline & 1.6021 & 5 & 44.4 & 4.8606 & 4.8110 & 4.8605 & 0.6321 \\
\hline & 1.3010 & 1 & 10.0 & 3.7183 & 3.7943 & 3.7219 & 0.3434 \\
\hline & control & 1 & & & & & \\
\hline \multirow{6}{*}{4} & 2.0000 & 8 & 80.0 & 5.8415 & 6.2422 & 5.7384 & 0.5208 \\
\hline & 1.9031 & 9 & 90.0 & 6.2817 & 5.9149 & 6.2201 & 0.3634 \\
\hline & 1.7782 & 8 & 80.0 & 5.8415 & 5.4929 & 5.8072 & 0.5004 \\
\hline & 1.6021 & 4 & 40.0 & 4.7471 & 4.8981 & 4.7484 & 0.6221 \\
\hline & 1.3010 & 1 & 10.0 & 3.7183 & 3.8814 & 3.7331 & 0.3472 \\
\hline & control & 0 & & & & & \\
\hline
\end{tabular}

\footnotetext{
${ }^{a}$ Percent mortalities were calculated by applying Abbott's formula (e.g., $P_{i}=p_{i}{ }^{\prime}-C / 1-C$, where $C$ is the natural mortality rate, $\left(P_{i}=i\right.$-th true mortality rate, and $P_{i}^{\prime}=$ observed $i$-th mortality rate. $)$ See text.
}

The toxicity data utilized here were obtained from the tests performed by the authors for determination of $48 \mathrm{~h} \mathrm{LC}_{50}$ of diquat (aquatic weedicide) on fathead minnows Pimephales promelas. Table II represents the results of four separate toxicity tests. The percent mortality rates of the exposure chambers were adjusted according to Abbott's formula (Booth, 1975). However, when the observed mortality in the toxicant chamber was the same as or less than that in the control chamber, the formula was not applied (Hubert, 1984).

The empirical probits, or observed probits (column 4 in Table II) were obtained by using the algorithm of the PROBIT program (Hubert and Schoch, 1984). Before drawing the common slope regression lines for the four datasets, the unweighted 
regression equation for each test was calculated. The common slope was obtained by using eq. (1). The variance of the slope for each regression line was calculated $\left(V\left(b_{i}\right)=\sigma_{i}{ }^{2} / \mathrm{S}_{\mathrm{Xx}}\right)$. From eq. (1), the common slope of the four regression lines was 3.3776. Thus, by employing $\bar{X}$ and $\bar{Y}$ calculated from Table I columns 1 and 4, the intercepts were obtained from eq. (2).

The expected probits (column 5 in Table II) were computed based on these regression equations and the working probits (column 6) were subsequently calculated (see Hubert, 1984). Other values were calculated and are summarized in Table III. This method generated an improved estimate of the slope for each test. For example,

$b_{1}={ }_{1} S_{X y}{ }^{\prime} /{ }_{1} S_{X X}=3.483948 / 1.089706=3.1971$.

Similarly, $b_{2}, b_{3}$, and $b_{4}$ were estimated to be $2.3423,3.4451$, and 3.2961 , respectively.

To test the hypothesis that the regression lines are parallel, the sum of $\chi^{2}$ for the individual lines and the total $\chi^{2}$ were calculated. The difference between these two $\chi^{2}$ values is a $\chi^{2}$ that tests parallelism (see Finney, 1971, pp. 107-108). From eq. (4),

$$
\begin{aligned}
A & =52.2277-232.1174 / 5.0517 \\
& =6.2793 \text { (d.f. }=12+3=15) \\
B & =1.6494+1.2424+0.0673+2.2805 \\
& =5.2396 \text { (d.f. }=m(d-2)=12) \\
A & -B=1.0397 \text { (d.f. }=m-1=3 \text { ). }
\end{aligned}
$$

The hypothesis, that the regression coefficients were the same for all the tests, was accepted and therefore the procedure was continued.

\begin{tabular}{|c|c|c|c|c|c|}
\hline $\begin{array}{l}\text { Test } \\
\text { No. }\end{array}$ & $\begin{array}{l}\sum n w \\
\sum n w X y^{\prime}\end{array}$ & $\begin{array}{l}\sum n w X \\
y^{\prime}\end{array}$ & $\begin{array}{l}\sum n w X^{2} \\
S_{X X}\end{array}$ & $\begin{array}{l}\sum n w y^{\prime} \\
S_{x y^{\prime} y^{\prime}}\end{array}$ & $\begin{array}{l}\sum n w y^{\prime 2} \\
S_{x y}\end{array}$ \\
\hline \multirow[t]{2}{*}{1} & 24.311 & 41.715 & 72.668 & 123.370 & 638.855 \\
\hline & 215.175 & 5.15822 & 1.089706 & 12.78784 & 3.483948 \\
\hline \multirow[t]{2}{*}{2} & 26.358 & 44.282 & 75.950 & 139.338 & 746.354 \\
\hline & 237.732 & 5.39688 & 1.553299 & 9.761108 & 3.638275 \\
\hline \multirow[t]{2}{*}{3} & 24.481 & 42.229 & 74.010 & 128.050 & 683.700 \\
\hline & 224.903 & 5.19886 & 1.167778 & 13.92700 & 4.023056 \\
\hline \multirow[t]{2}{*}{4} & 23.539 & 40.713 & 71.658 & 124.049 & 669.490 \\
\hline & 218.645 & 5.24944 & 1.240891 & 15.76184 & 4.090088 \\
\hline
\end{tabular}

For $V\left(b_{i}\right)=1 / i S_{X X}$, eq. (1) was modified. The common slope of the ML probit lines was:

\section{TABLE III}

Summary of statistics generated by the GRANDPRO program. 
$b=\frac{\sum_{i=1}^{m}\left(b_{i}\right)\left({ }_{i} S_{X X}\right)}{\sum_{i=1}^{m}{ }_{i} S_{X X}}$

$=15.2358 / 5.0518=3.0159$.

By knowing $\bar{X}_{i}$ and $\bar{y}^{\prime}{ }_{i}$ from Table III, improved ML probit lines with a common slope were calculated from eq. (2)" . For example, the intercept of Test 1 was -0.0198 . The log estimate of $\mathrm{LC}_{50}$ for test 1 was:

$M_{1}=\frac{5+0.0198}{3.0159}=1.6644$.

The values of $M_{2}, M_{3}$, and $M_{4}$ were $1.5853,1.6509$, and 1.6342 , respectively.

Variance of each $\mathrm{LC}_{50}, V\left(M_{i}\right)$, was computed with the eq. (5). For test 1:

$V\left(M_{i}\right)=\frac{1}{3.0159^{2}}\left[\frac{1}{24.311}+\frac{(1.6644-1.7169)^{2}}{1.0897}\right]=0.00480$

The same calculation resulted in $V\left(M_{2}\right)=0.00540, V\left(M_{3}\right)=0.00490$, and $V\left(M_{4}\right)=0.00528$. The heterogeneity of the separate estimates $\left(M_{1}, M_{2}, M_{3}\right.$ and $\left.M_{4}\right)$ was tested with eq. (6):

$\chi^{2}=2104.55-\frac{1286.75^{2}}{786.99}=0.68$.

Since $\chi^{2} 0.95,3=7.8$, no evidence of discrepancies in the four values of $M\left(\mathrm{LC}_{50}\right)$ were indicated. Therefore, from eq. (7) the mean $\log \left(\mathrm{LC}_{50}\right)$ for diquat is:

$M=1286.8 / 787.0=1.6350$.

The most appropriate $\mathrm{LC}_{50}=10^{1.6350}=43.15 \mathrm{mg} / \mathrm{l}$. The 'grand probit line' for diquat is obtained from eq. (2) ${ }^{\prime \prime \prime}$ :

$Y=3.0159 X+0.0690$.

The standard error of $M, s_{M}$, was obtained with eq. (8):

$V(M)=1 /(208.3+185.2+204.1+189.4)$

$s_{M}=0.0356$.

The approximate $95 \%$ confidence interval of the mean $L_{50}$ is $\left(10^{1.6350-1.96 \times 0.0356}\right.$, $\left.10^{1.6350+1.96 \times 0.0356}\right)=(36.75$ and 50.67$) \mathrm{mg} / \mathrm{l}$. The comparison between the four separate probit lines estimated from the individual test results and the grand probit line which was based on the four separate test data are presented in Figs. 1 and 2. 

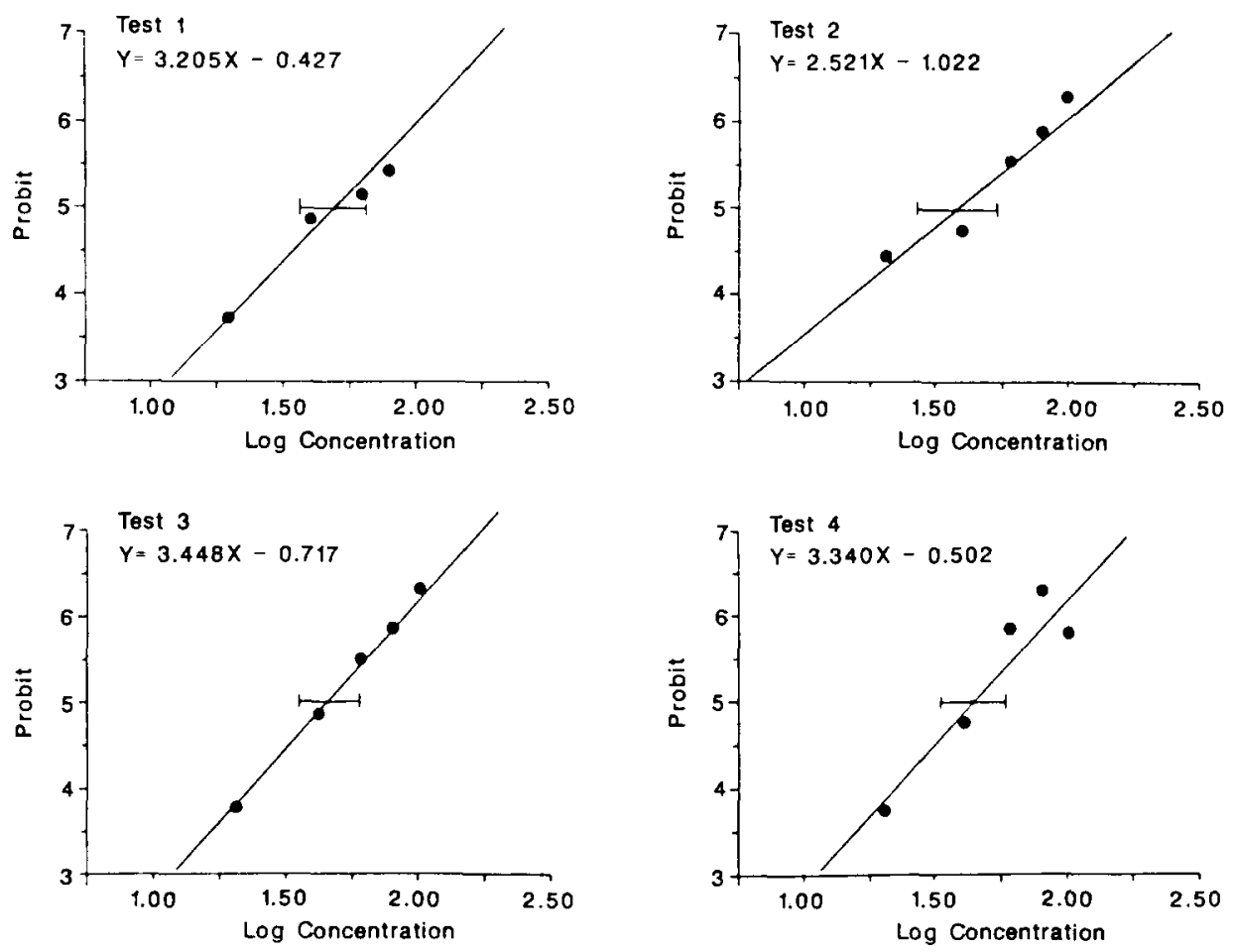

Fig. 1. Four probit lines drawn from the individual test results. The horizontal bar represents $95 \%$ confidence interval of each $\mathrm{LC}_{50}$ value.

\section{DISCUSSION AND SUMMARY}

As mentioned earlier, it would be very advantageous to have one best-fit probit line and a single $\mathrm{LC}_{50}$ value for one test compound and one test species even though several toxicity tests were conducted over time with varying results. With the proposed statistical procedure, it is possible to combine multiple test results and generate one best-fit probit line. Before this method can be applied, however, one must assume that all the tests have been carried out with the best effort to meet the experimental conditions and that each assay proved statistically valid with the chisquare test.

It is evident from our test data with diquat, that the 'grand probit line' (Fig. 2) provides a good estimate of the separate probit lines shown in Fig. 1. Therefore, the 'grand probit line' would appropriately represent all test results which were obtained under somewhat different test conditions, but were still within the boundary of standard test conditions. As a result of combining several datasets for drawing 


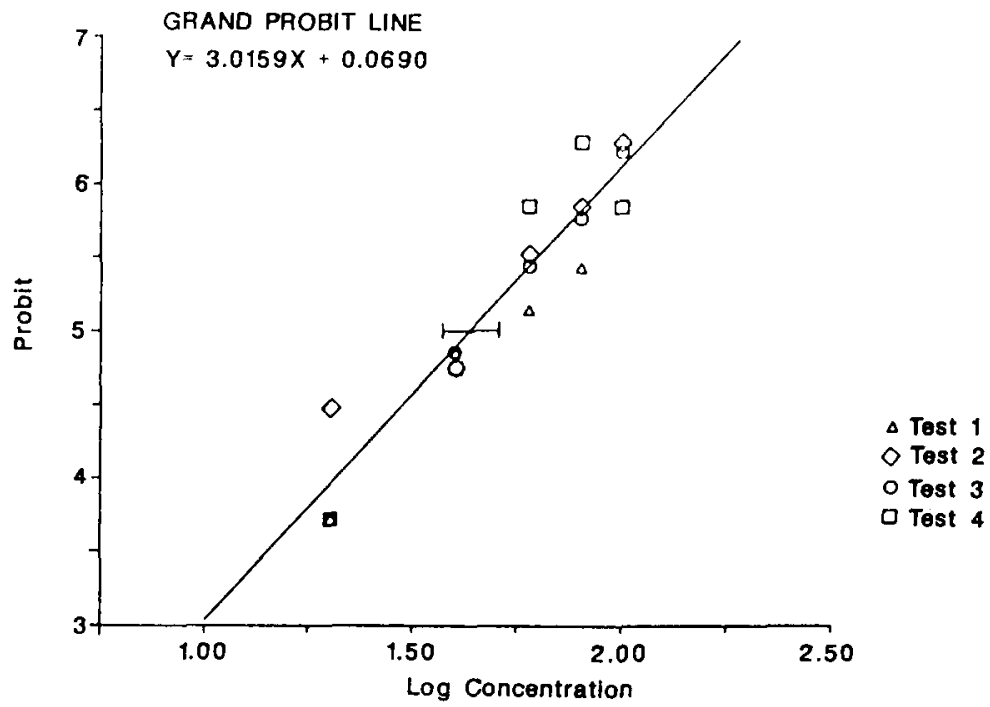

Fig. 2. A grand probit line estimated from the four test results by the GRANDPRO program.

one probit line, the confidence interval of $\mathrm{LC}_{50}$ became narrower than the ones shown in Fig. 1.

The GRANDPRO program is written in BASIC language for IBM PC.** The program outputs are: a grand probit line equation: $\mathrm{LC}_{50}$ and its associated $95 \%$ confidence interval; two hypothesis test results; and a graphical display of the grand probit line on the screen.

\section{REFERENCES}

Booth. G.D., 1975. On the use of Abott's formula: a correction for natural response. Biometrics 31, 590. Buikema, A.L. Jr., B.R. Niederlehner and J. Cairns, Jr., 1982. Biological monitoring: Part IV. Toxicity testing. Water Res. 16, 239-262.

Finney, D.J., 1964. Statistical method in biological assay. C. Griffin, London.

Finney. D.J., 1971. Probit analysis. Cambridge Univ. Press, Cambridge, 333 pp.

Hubert, J.J., 1984. Bioassay. Kendall-Hunt Publ. Co., Dubque, Iowa, 180 pp.

Hubert, J.J. and J.P. Shock, 1984. Probit: an interactive program in BASIC for probit analysis. Statistical Series No. 1984-160, Univ. of Guelph, Ontario, Canada.

Rand, G.M. and S.R. Petrocelli, 1985. Fundamentals of aquatic toxicity. Hemisphere Publ. Co., Washington. pp. 55-56.

**The GRANDPRO computer program written in BASIC for an IBM PC is available from Peter G. Meier. Please send a formatted $5^{1 / 4}$ " diskette with a self-addressed stamped envelope. 